\title{
MORPHOLOGICAL AND MECHANICAL PROPERTIES OF POLYPROPYLENE/EPOXIDIZED NATURAL RUBBER THERMOPLASTIC VULCANIZATES TREATED WITH MALEIC ANHYDRIDE-GRAFTED POLYPROPYLENE
}

\author{
N. Mohamad", Z. Nur Sharafina, H.E. Ab Maulod, M. Y. Yuhazri and \\ A.R. Jeefferie \\ ${ }^{1}$ Department of Engineering Materials, Faculty of Manufacturing Engineering, \\ Universiti Teknikal Malaysia Melaka, \\ 76100 Durian Tunggal, Melaka, Malaysia \\ Email: noraiham@utem.edu.my \\ Phone: +606-555-2000; Fax: +606-331-6247
}

\begin{abstract}
This research is to investigate the morphological and mechanical properties of thermoplastic vulcanizates, polypropylene/epoxidized natural rubber (PP/ENR) when treated with maleic anhydride-grafted polypropylene (Mah-PP). The PP/ENR thermoplastic vulcanizate was prepared using a two-stage melt compounding method using an internal mixer at specified temperature and time. Then it was mixed and dynamically vulcanized using a semi-EV sulfur curing system in an internal mixer at $170^{\circ} \mathrm{C}$ for 10 minutes. Mah-PP was varied from 5,10 to $15 \%$ in the samples. Tensile and hardness testing were performed on the sample to characterize the mechanical properties of the PP/ENR vulcanizates. The morphology was observed under a scanning electron microscope (SEM) at magnifications of 500x and 2000x. 50/50 PP/ENR vulcanizates showed improvement of up to $400 \%$ elongation at break compared to pure PP. In contrast, the tensile strength and hardness decreased as the amount of PP decreased. However, the tensile properties of the vulcanizates improved with the addition of Mah-PP compatibilizer into the blend during the compounding process. This was contributed by enhancement in miscibility between thermoplastic and rubber molecules with the presence of the compatibilizer. Morphological observation of the vulcanizates showed that two-phase system ENR phase were dispersed as domains in a continuous thermoplastic matrix. The domain size of dispersed ENR particles decreased with the addition of compatibilizer. In conclusion, the addition of Mah-PP improved the tensile strength and Young's modulus of the thermoplastics matrix. The morphologies of tensile fractured surfaces of treated PP/ENR blends revealed better interaction between PP and ENR with the presence of Mah-PP.
\end{abstract}

Keywords: Polypropylene; epoxidized natural rubber; Mah-PP compatibilizer; morphological; mechanical properties.

\section{INTRODUCTION}

The blending of two or more types of polymers is a useful technique for the preparation and development of materials with properties superior to those of the individual constituents (Findik, Yilmaz, \& Koksal, 2004; Jeffrey, Tarlochan, \& Rahman, 2011; Bhaskar, \& Sharief, 2012). The purpose of blending the rubber is to improve the physical and mechanical properties as well as to modify processing characteristics and reduce the cost of the final product. However, most polymer blends are immiscible and 
usually exhibit phase-separated morphology and poor interfacial adhesion between the phases (Bluma, Mauricio, \& Pedro, 2004). The interfacial adhesion can be improved by introducing a third component into an immiscible binary system that will either interact chemically with both the phases or will have a specific interaction with one phase and a physical interaction with the other (Tedesco et al., 2002). This phenomenon can be explained as an improvement in the compatibilization of the blend. Commonly, compatibilization can lead to a finer phase structure and enhanced interfacial adhesion (Mangaraj, 2002). The compatibilizer may form an interface between the immiscible blend components, so that imposed stresses can be transferred between the phases via the covalent bonds along the copolymer backbone. However, an understanding of the blend morphology is important because the properties of the polymer blends are strongly dependent on it (Favis, 1990; Umar, Zainudin, \& Sapuan, 2012). Addition of a suitable compatibilizer was found to result in the development of a finer scale of dimensions of the dispersed phase in the matrix, as well as enhancement of physicomechanical properties of the vulcanizates (Setua \& Gupta, 2007; Ibrahim, Sapuan, \& Faieza, 2012; Hariprasad, Dharmalingam, \& Praveen Raj, 2013).

Thermoplastic elastomers (TPEs) exhibit functional properties of conventional vulcanized rubber, yet can be processed on thermoplastic fabrication equipment. Such materials can be produced either as block copolymers or as blends. The great majority of TPEs have hetero-phase morphology. The TPEs based on polyolefin rubberthermoplastic compositions have developed along two distinctly different lines. One consists of a simple blend and classically meets the definition of a thermoplastic elastomeric olefin (TPO). In the other class, the rubber phase is dynamically vulcanized, giving rise to thermoplastic vulcanizates (TPVs) or dynamic vulcanizates (DVs). The TPVs are characterized by finely dispersed micron-sized cross-linked rubber particles distributed in a thermoplastic matrix (Nakason, Worlee, \& Salaeh, 2005; Ravi Sankar, Srikant, Vamsi Krishna, Bhujanga Rao, \& Bangaru Babu, 2013). There are many articles reporting on TPEs prepared from polymer blends. The most widely used plastic is polypropylene (PP). PP is an additional polymer with a large molecular weight distribution (Meyer \& Keurentjes, 2005). It has a wide range of applications due to its unique properties such as high melting temperature, low density, high chemical resistance, and resistance to heat. On the other hand, PP exhibits poor impact strength, which raises limitations in several other applications (da Costa et al., 2010). Various rubbers were blended with PP to prepared TPEs such as ethylene-propylene-diene rubber (EPDM), styrenic block copolymer, ethylene propylene rubber (EPR), and rubber waste from ground tread layers of truck tires blended with polyethylene to prepared TPEs (Tanrattanakul et al., 2009).

Epoxidized natural rubber (ENR) is a material of great interest, exhibiting a double functionality for cross-linking (double bonds and epoxy site) while retaining most of the properties of natural rubber (Pire et al., 2010). The epoxidation of natural rubber can be performed using peracid generated from the reaction of formic acid and hydrogen peroxide (Liau, 1998). The properties of ENR are gradually changed with increasing degree of epoxidation (Liau, 1998). The presence of epoxy groups in the rubber chain has imparted great properties to natural rubber, such as oil resistance, low gas permeability, good wet grip and high damping characteristics (Mohamad et al., 2008; 2009; 2010; Thitithammawong et al., 2007). Studies conducted on PP/ENR or ENR/PP blend were focused more on studying the effect of dynamic vulcanization (Nakason et al., 2006; 2008; Thitithammawong et al., 2007) or irradiation (Senna et al., 2008) on the properties of the blend. There is limited effort on studying the effect of the 
PP: ENR ratio and chemical treatment on its physical or mechanical properties. In this paper, we have investigated the effect of various levels of ENR and compatibilizer addition on the mechanical properties of polypropylene/epoxidized natural rubber blends. The properties were supported by morphology analysis on the tensile fracture surfaces.

\section{EXPERIMENTAL METHOD}

\section{Materials}

The PP used in this research is polypropylene homo-polymer TITANPRO 6531(isotactic type) with a specified melt flow index of $3.5 \mathrm{~g} / 10$ minutes. It was supplied by Titan PP Polymers (M) Sdn. Bhd. ENR was supplied by the Malaysian Rubber Board under the trade name of ENR 50 with 53\% epoxidation. The average Mooney viscosity [measured at ML $(1+4) 100^{\circ} \mathrm{C}$ ] was 85.5 and the average specific gravity at approximately $25^{\circ} \mathrm{C}$ was 0.9366 . Maleic anhydride-grafted polypropylene (Mah-PP) supplied by Sigma Aldrich was used as the compatibilizer. Sulfur was used as te vulcanizing agent while zinc oxide and stearic acid were used as activators in the sulfur curing system. The sulfur, zinc oxide, and stearic acid were purchased from Sin Rubtech ${ }^{\circledR}$.

Table 1. Formulation of PP/ENR blend.

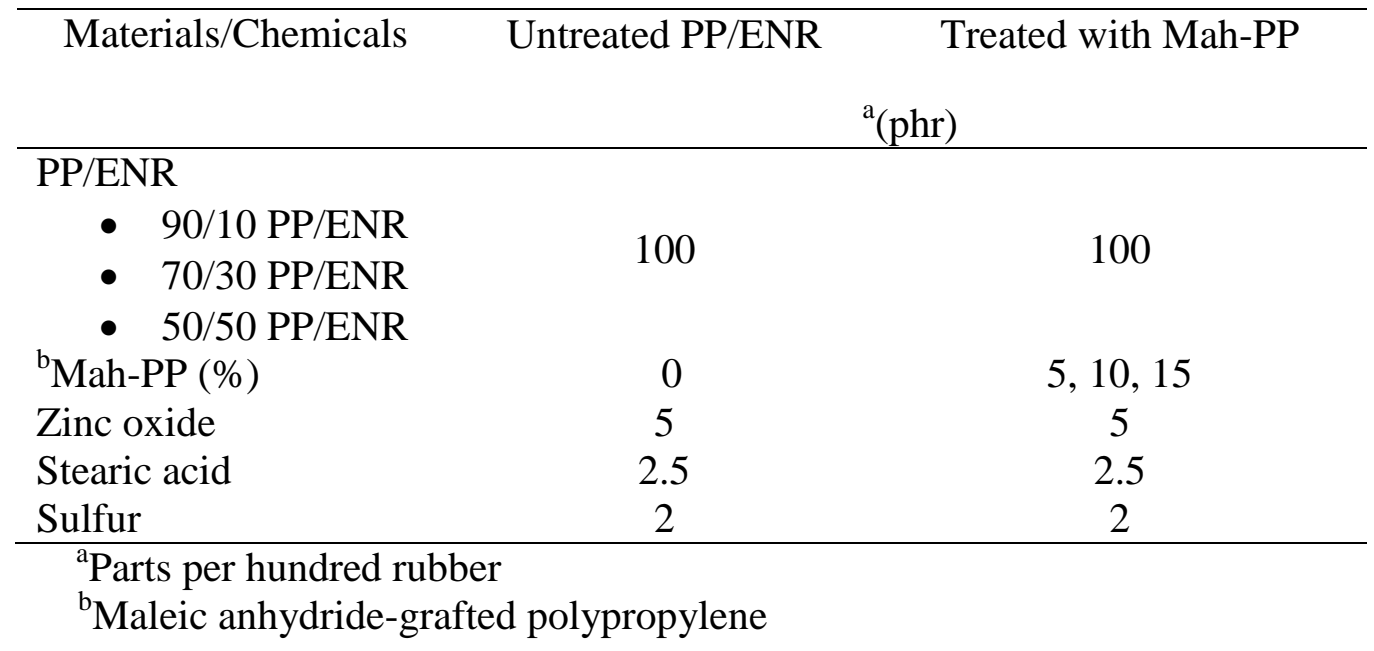

\section{Mixing and Preparation of Sample}

Table 1 shows the formulation of the PP/ENR blends. The blending was carried out using a HAAKE Rheomix OS internal mixer in two stages: 1) masterbatch compounding, and 2) mixing and dynamic vulcanization of the PP and ENR masterbatch. In Stage 1, mixing was carried out at a constant rotor speed of $60 \mathrm{rpm}$ at a temperature of $60^{\circ} \mathrm{C}$ for 6 minutes. During this first stage, the masterbatch of ENR, zinc oxide and stearic acid, after mixing for 6 minutes, was discharged to cool down to room temperature. In Stage 2, mixing was conducted using an internal mixer at a rotor speed of $60 \mathrm{rpm}, 170^{\circ} \mathrm{C}$ for 10 minutes. For the untreated blend, the PP was first melted for 2 min in the mixing chamber followed by addition of the ENR masterbatch prepared in Stage 1 . Then, mixing was continued for another 7 minutes before sulfur was added and mixed for another 1 minute to complete the dynamic vulcanization. For treated samples, 
compatibilizer was added at the second minute and mixed for three minutes before the ENR masterbatch was added at the fifth minute. After Stage 2, the blend was postulated to exhibit partial vulcanization. Then, it was immediately discharged and left to cool down at room temperature for 24 hours. The produced TPV sheets were pressed using a GT7014-A hot press from Gotech for about 5 minutes at a temperature of $185^{\circ} \mathrm{C}$ and pressure of $1800 \mathrm{~kg} / \mathrm{cm}^{2}$. Subsequently, the samples were cooled down under pressure to room temperature for 5 minutes. Samples were cut into the desired sizes according to specific standards for various testing. Cut samples were left to condition at room temperature for 24 hours before further testing.

\section{Mechanical Properties}

A tensile test was carried out according to BS 6747. In this test, standard "dumbbell" or "dogbone" shaped specimens at $1 \mathrm{~mm}$ thickness were used. Dumbbell specimens of PP/ENR blends were cut using a die cutter JISK 6251. The tensile test was performed using INSTRON (Model 4301) Universal Testing at a crosshead speed of $100 \mathrm{~mm} / \mathrm{min}$, in accordance with BS 6747 at room temperature, $25 \pm 5^{\circ} \mathrm{C}$. The hardness of the samples was tested using a Shore Type D CV durometer according to ASTM D2240. The standard test specimen for ASTM D2240 is $64 \times 12.7 \times 3.2 \mathrm{~mm}\left(2 \frac{1}{2} \times 1 / 2 \times 1 / 8\right.$ inch). The most common specimen thickness is $3.2 \mathrm{~mm}(0.125 \mathrm{inch})$, but the preferred thickness is $6.4 \mathrm{~mm}(0.25 \mathrm{inch})$ because it is less likely to bend or crush.

\section{Morphological Examination using Scanning Electron Microscope (SEM)}

An examination of the blend surfaces was carried out using a scanning electron microscope (SEM) ZEISS (EVO 50) at magnifications of $500 \mathrm{x}$ and 2000x. For every sample, when taking micrographs a minimum of three frames at each magnification was taken to ensure a high confidence level in the analysis.

\section{RESULTS AND DISCUSSION}

\section{Mechanical Properties}

A stress-strain curve is important in determining the differences in deformation that are characteristic of blends under an applied load. The stress-strain curves of untreated 90/10 PP/ENR, 70/30 PP/ENR, and 50/50 PP/ENR samples are shown in Figure 1. As can be observed, the sample with low ENR loading (90/10 PP/ENR) exhibits stressstrain properties close to those of a brittle material. It shows very high initial modulus with a definite yield point. The addition of ENR changed the nature of the stress-strain curve considerably. The PP/ENR blends containing a higher proportion of ENR have distinct elastic and inelastic regions. This is observed since the properties of rubberplastic blends are determined by (1) the material properties of the rubber and plastic phases, (2) rubber/plastic proportions, (3) the phase morphology, and (4) the interaction at the interface (Bhowmick and Stephens, 2001). The elastic modulus of the blends is found to be considerably reduced with the increase in rubber concentration. On the other hand, the inelastic region of the blend was expanded prior to yielding and exhibits an excellent improvement in toughness, which is very similar to an elastomer. The improved rubbery behavior of 50/50 PP/ENR compared to 90/10 PP/ENR and 70/30 $\mathrm{PP} / \mathrm{ENR}$ can be explained in terms of the phase inversion of ENR from dispersed to 
partially continuous phase (Danesi et al., 1978) on passing from 90/10 PP/ENR to 50/50 PP/ENR

Table 2 tabulates the values of tensile strength (TS), Young's modulus (E), elongation at break (EB) and hardness of the untreated PP/ENR blends as a function of weight percentage of ENR. It is clear that 90/10 PP/ENR exhibits the highest tensile strength and Young's modulus. Since the tensile strength of PP/ENR blends is highly dependent on the relatively high strength of PP phase, the observed decrease in both values with the increase in ENR content is to be expected. The outstanding tensile strength of pure PP is due to the ability of its structure to be strain-crystallized during stress loading. As a result, the presence of soft rubber phase with branches of epoxide groups distorts the linearity of PP chains to be realigned and crystallized, which in turn decreases the maximum stress that can be withstood by the PP/ENR blends before plastic deformation takes place. Moreover, the observed declining trend of TS in Figure 2 with increasing ENR content may be due to a substantially poor interfacial adhesion between the non-polar PP and polar ENR phases, which causes poor stress transfer between the continuous PP matrixes with dispersed phase. The poor interfacial adhesion causes premature failure as a result of the usual crack opening mechanism.

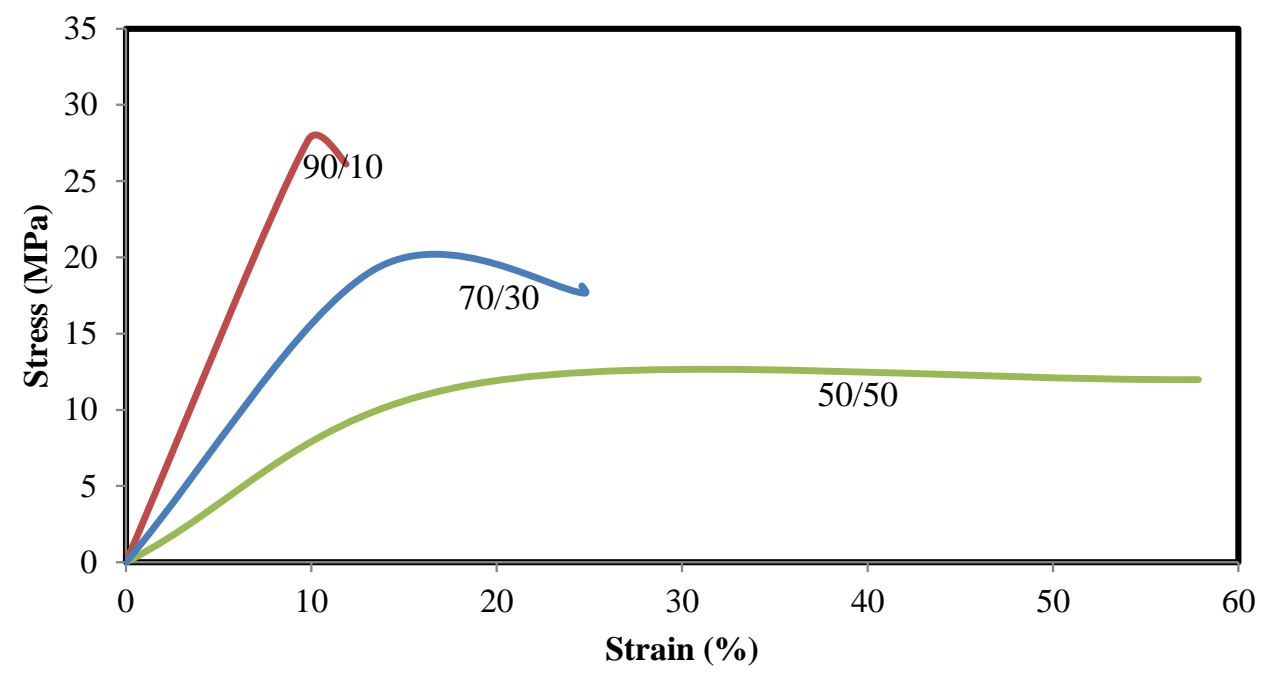

Figure 1. Stress-strain curve of the PP/ENR blend samples.

Table 2. Mechanical properties of ENR filled various loadings of untreated PP/ENR blend.

\begin{tabular}{ccccc}
\hline Properties & \multicolumn{4}{c}{ Type of sample } \\
& 100 & $90 / 10$ & $70 / 30$ & $50 / 50$ \\
& PP & PP/ENR & PP/ENR & PP/ENR \\
\hline Tensile strength (MPa) & 28.31 & 25.75 & 18.32 & 11.85 \\
Young's modulus (MPa) & 388.13 & 378.15 & 293.16 & 151.62 \\
Elongation at break, (\%) & 11.03 & 11.65 & 20.90 & 58.39 \\
Hardness (Shore D) & 74.14 & 69.87 & 62.55 & 52.56 \\
\hline
\end{tabular}

The elongation at break (EB) of PP/ENR blends was found to increase with the addition of ENR content. This increment was contributed by the soft rubber phase of ENR. Addition of ENR reduces the stiffness of the blends, which resulted in lower resistance to plastic deformation. As stated in Table 2, the pure 90/10 PP/ENR shows the highest hardness in the range of 70 to 72 Shore D, compared to 70/30 PP/ENR and 
50/50 PP/ENR. Hardness indirectly represents the stiffness or rigidity of the material, which measures the ability of the material to be scratched or indented by other material (Grellman \& Seidler, 2007). The stiffness decreases as the rubber content increases in the sample. It was clearly observed that 50/50 PP/ENR samples show the lowest hardness in the range of 52 to 54 Shore D, which indicates reduction of about $30 \%$ compared to pure PP. This is due to the elastic properties of rubber phase in the blend. In addition, it shows good agreement with the obtained Young's modulus (Table 2).

Figures 2 and 3 show tensile fracture surfaces of pure PP, untreated 90/10 $\mathrm{PP} / \mathrm{ENR}, 70 / 30 \mathrm{PP} / \mathrm{ENR}$ and 50/50 PP/ENR blends at magnifications of 500x and 2000x. Most of the fracture surfaces show characteristics of ductile fracture under uniaxial tensile loads, with the obvious pattern of shear yielding on the surface. The mechanism is more severe in high ENR content samples due to the plastic deformation that took place in the materials before fracture. Furthermore, there are spherical shaped dimples pulled out of either PP domains or ENR domains from continuous matrix, especially on the fracture surfaces of the 70/30 PP/ENR and 50/50 PP/ENR blends. In the fracture surfaces of the 90/10 PP/ENR and 70/30 PP/ENR blends, ENR were dispersed as domains in the continuous PP phase. This is the stage where ENR is present in the intra-spherulitic structure of PP (George, Varughese, \& Thomas, 2000). In Figure 2(c), the ENR phase started to enlarge its size and formed bigger ENR domains in the PP matrix. In addition, there are smaller PP domains (PP particles) situated in ENR phases, as depicted in Figure 3(c). This clearly exhibits the condition where occlusions of ENR phase started to form as the concentration of rubber matrix was higher than $45 \mathrm{wt} \%$ in the blend, with the presence of PP particulates trapped in the ENR regions.

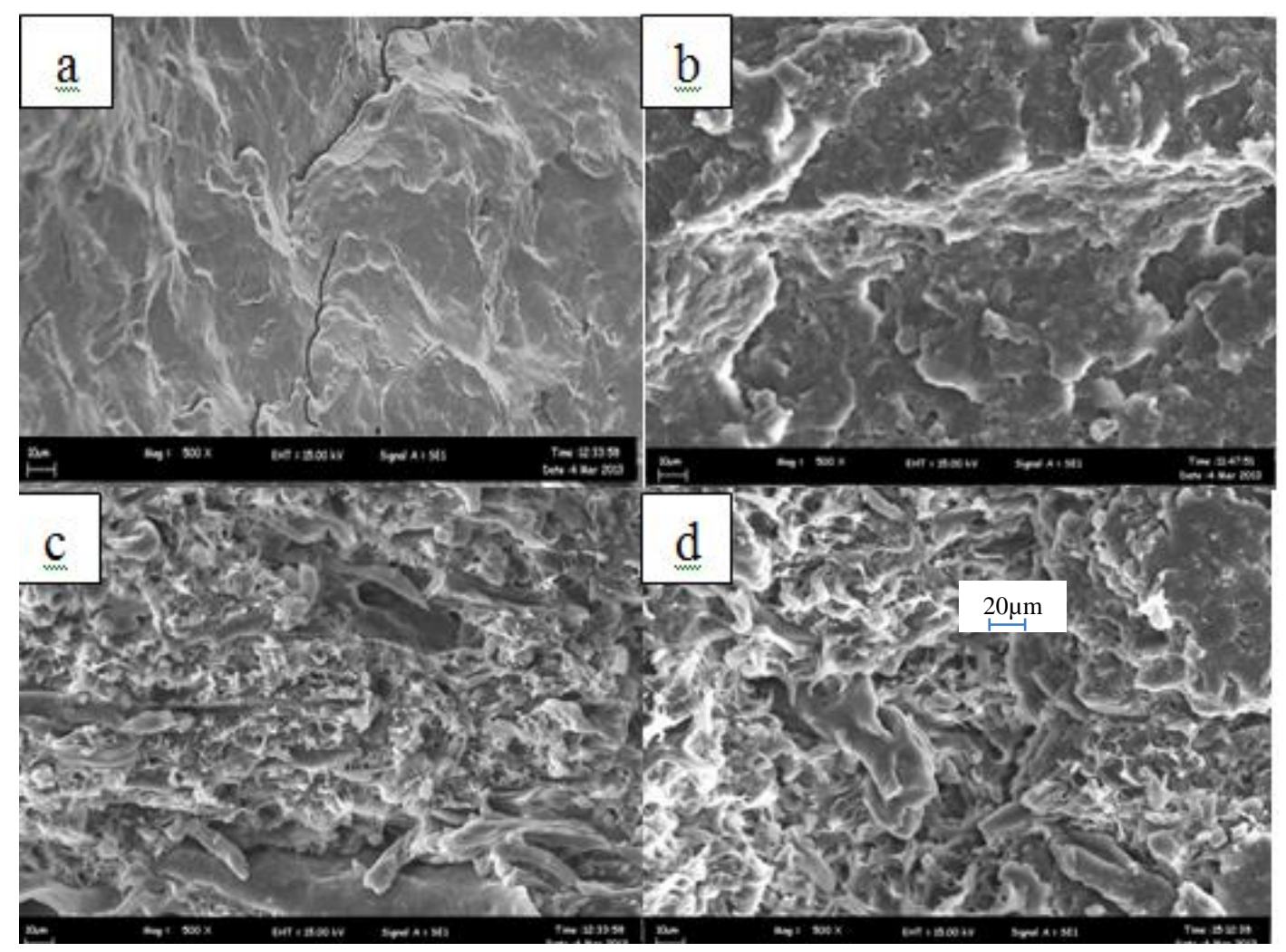

Figure 2. Scanning electron micrograph of untreated (a) pure PP, (b) 90/10 PP/ENR, (c) 70/30 PP/ENR and (d) 50/50 PP/ENR at magnification of 500x. 


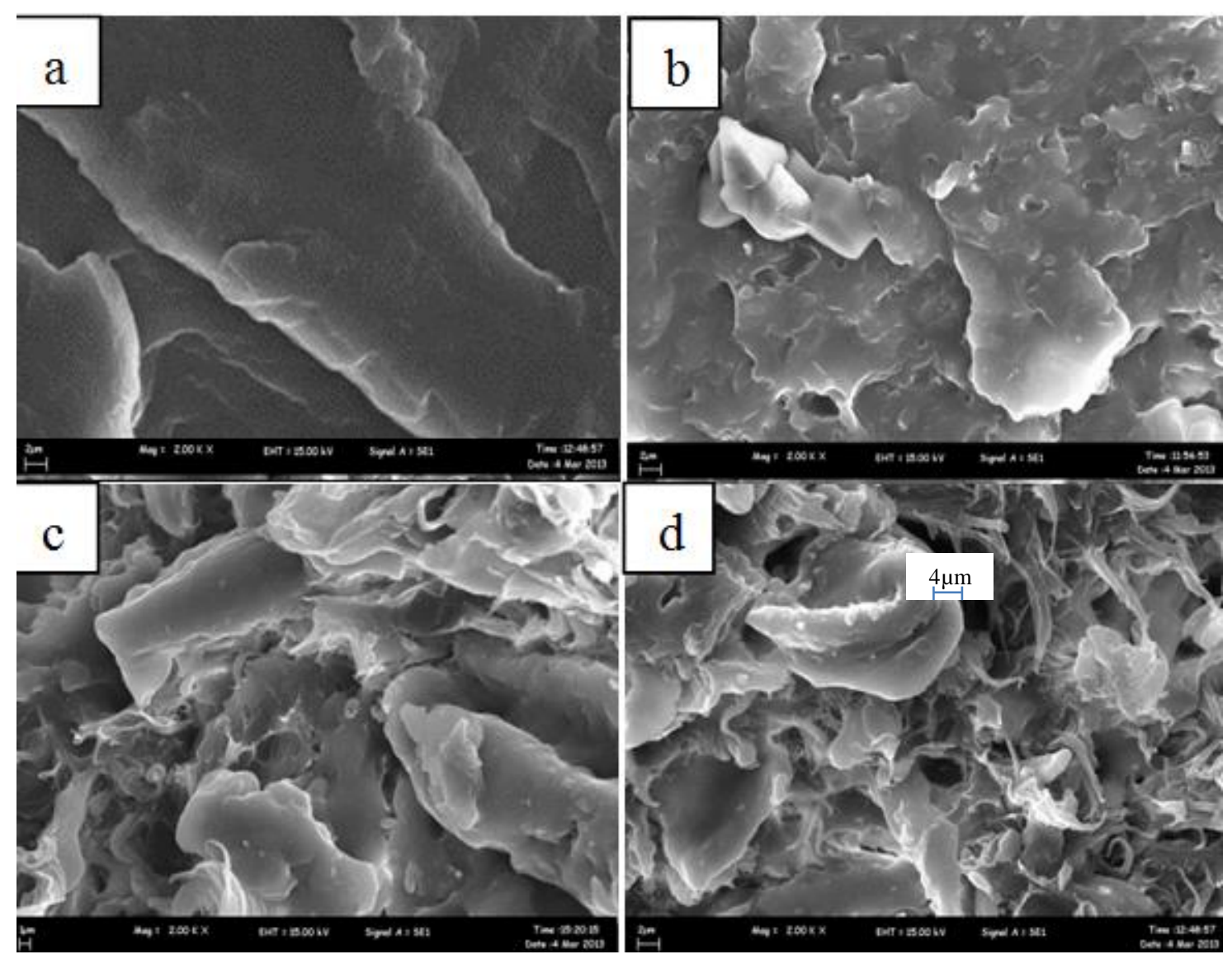

Figure 3. Scanning electron micrograph of untreated (a) pure PP, (a) 90/10 PP/ENR, (b) $70 / 30 \mathrm{PP} / \mathrm{ENR}$ and (c) 50/50 PP/ENR at magnification of 2000x.

\section{Mechanical Properties and Morphology of Compatibilized Blends}

The mechanical properties of polymer blends were improved with the addition of maleic anhydride-grafted polypropylene as compatibilizer. Figure 4 shows the effect of different compatibilizer content on tensile strength (TS) and Young's modulus (E) of treated 90/10 PP/ENR blends. The increase of Mah-PP loading from 5\%, 10\%, to $15 \%$ in PP/ENR blends increases the tensile strength up to $11 \%$ compared to untreated samples. This increase in tensile strength was due to the increase in interfacial adhesion between PP and ENR phases, which is evident in the SEM micrographs in Figure 5. The variation of E values at different Mah-PP concentrations is shown in Figure 4 (b). It was found to increase with the increase in concentration of Mah-PP in the blends. This was in line with the increase in TS, which is directly proportionate to the interaction between PP and ENR with the presence of Mah-PP.

Figure 5 shows the effect of Mah-PP on tensile fracture surfaces of 90/10 PP/ENR blends. Every fracture surface shows fibrous structure from shear yielding during plastic deformation. This is most severe in samples with incorporation of more than 10\% Mah-PP. Figure 5(b) for the incorporation of 10\% Mah-PP displays broader tearing lines compared to Figure 5(a) and (c). The increase in fibrous structure could be explained by the good interaction between PP and ENR matrix with the presence of Mah-PP. The uniform dispersion of ENR in PP matrix altered the crack path, which leads to more resistance for crack propagation and results in higher tensile strength. The 
presence of more tear lines on the fracture surface of PP/ENR blends with Mah-PP designates the effects of increased interaction between phases, thus improving the compatibility and enhancing the tensile strength (Noriman, Izmail, \& Rashid, 2010). However, the effect of Mah-PP to improve the tensile properties of PP/ENR blends almost achieves its saturation point at $15 \%$, as clearly depicted in Figure 5(c). The fracture surface consists of the highest degree of fibrous structure but with shorter tear lines, which indicates the better interaction between PP and ENR compared to the sample at 5\% Mah-PP, but experienced stiffening in polymeric chains deformation at the 15\% Mah-PP level. This was in good agreement with the E values in Figure 4(b).

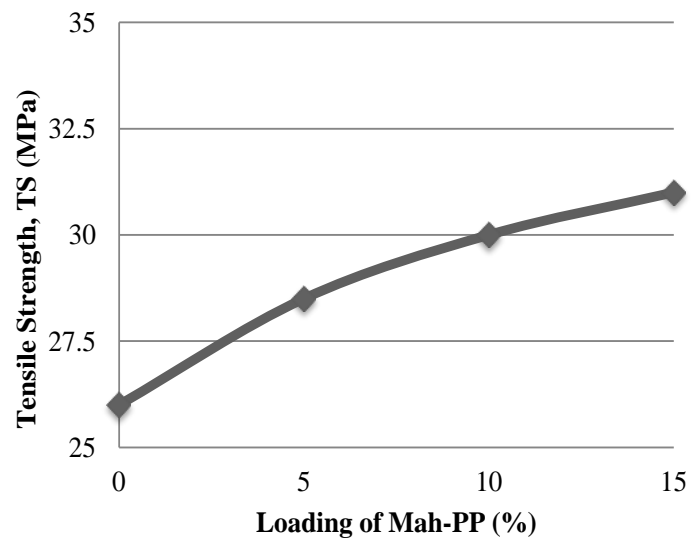

(a)

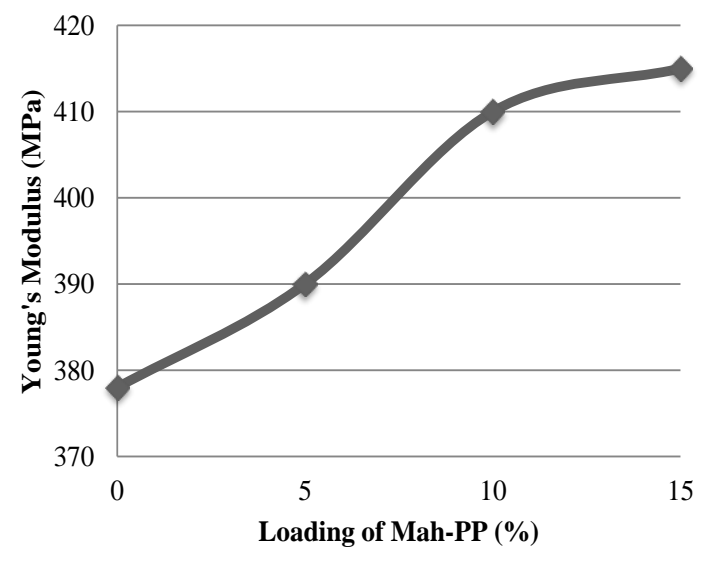

(b)

Figure 4. (a) Tensile strength of treated 90/10 PP/ENR at different levels of Mah-PP, (b) Young's modulus of treated 90/10 PP/ENR at different levels of Mah-PP.
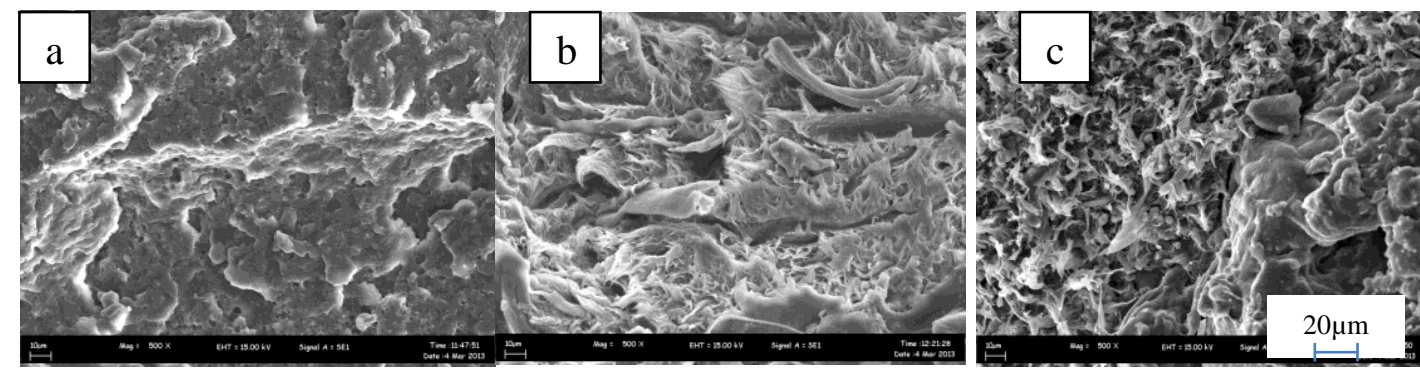

Figure 5. SEM micrographs of 90/10 PP/ENR blend compatibilized with Mah-PP: (a) $5 \%$ Mah-PP, (b) 10\% Mah-PP, (c) 15\% Mah-PP.

\section{CONCLUSION}

As a conclusion, it was found that the thermoplastic vulcanizates of PP/ENR at high rubber content show improved toughness and flexibility. The elongation at break values increases as the rubber content increases in the blend. However, the addition of rubber content lowers the tensile strength, Young's modulus and hardness of the blend due to the reduction in PP phases. These properties are substantially due to the rigidity of PP chains and its ability to be strain-crystallized. In contrast, the presence of cross-linking in rubber matrix of PP/ENR imparted elastic behavior and decreased the Young's modulus of PP due to rubber-like properties introduced by the ENR. On the other hand, the addition of Mah-PP improves the tensile strength and Young's modulus of the thermoplastics matrix. This was clearly proven when the 90/10 PP/ENR blend showed 
an increment of tensile strength to $\sim 27 \mathrm{MPa}$ with the presence of $15 \%$ Mah-PP compared to $\sim 25 \mathrm{MPa}$ in untreated PP/ENR blend. The morphologies of tensile fractured surfaces of treated PP/ENR blends reveal better interaction between PP and ENR with the presence of Mah-PP. This was depicted by the degree of severity of its fibrous structure due to shear yielding during plastic deformation of the samples.

\section{ACKNOWLEDGMENTS}

The authors are grateful to the Universiti Teknikal Malaysia Melaka for financial support through a short-term grant research with project no. PJP/2011/FKP (33A) S999.

\section{REFERENCES}

Bhowmick A. K. \& Stephens, H. L. (2001). Handbook of Elastomers. Second Edition, Revised and Expanded. Marcel Dekker Inc.

Bhaskar, H. B., \& Sharief, A. (2012). Effect of solutionizing on dry sliding wear of A12024-Beryl metal matrix composite. Journal of Mechanical Engineering and Sciences, 3, 281-290.

Bluma, G. S., Mauricio, S. M. A., \& Pedro, I. C. G. (2004). The reactive compatibilization of NBR/EVA blends with oxazoline-modified nitrile rubber. European Polymer Journal, 40, 2185-2194.

da Costa, H. M., Ramos, V. D., da Silva, W. S., \& Sirqueira, A. S. (2010). Analysis and optimization of polypropylene (PP)/ethylene-propylene-diene monomer (EPDM) /scrap rubber tire (SRT) mixtures using RSM methodology. Polymer Testing, 29, 572-578.

Danesi, S. \& Porter, R. S. (1978). Blends of isotactic polypropylene and ethylenepropylene rubbers. Rheology, morphology and mechanics. Polymer, 19, 448457.

Favis, B. D. (1990). The effect of processing parameters on the morphology of immiscible binary blend. Journal of Applied Polymer Science, 39(2), 285-300.

Findik, F., Yilmaz, R., \& Koksal, T. (2004). Investigation of mechanical and physical properties of several industrial rubbers. Material \& Design, 25, 269-276.

George, S., Varughese, K. T., \& Thomas, S. (2000). Molecular transport of aromatic solvents in isotactic propylene/ acronitrile-co-butadine rubber blends. Polymer, 41, 579-594.

George, S., Varughese, K. T., \& Thomas, S. (2000). Thermal and crystallisation behaviour of isotactic polypropylene/nitrile rubber blends. Polymer, 41, 54855503.

Grellman, W. \& Seidler, S. (2007). Polymer Testing. Munchen, Germany: Hanser.

Hariprasad, T., Dharmalingam, G., \& Praveen Raj, P. (2013). A study of mechanical properties of banana-coir hybrid composite using experimental and fem techniques. Journal of Mechanical Engineering and Sciences, 4, 518- 531.

Horack, Z., Fort, D., Hlavata, F., Lednicky, F., \& Vecerka, F. (1996). Compatibilization of high-compact polystyrene/polypropylene blends. Polymer, 37(1), 65-37.

Ibrahim, M. S., Sapuan, S. M., \& Faieza, A. A. (2012). Mechanical and thermal properties of composites from unsaturated polyester filled with oil palm ash. Journal of Mechanical Engineering and Sciences, 2, 133-147.

Ismail, H. \& Suryadiansyah, R. (2001). Thermoplastic elastomer based on polypropylene/natural rubber and polypropylene/recycle blend. Polymer Testing, $21,385-395$. 
Ismail, H., Salmah, \& Nasir, M. (2001). Dynamic vulcanization of rubberwood-filled polypropylene/natural rubber blends. Polymer Testing, 20, 819-823.

Jeffrey, K. J. T., Tarlochan, F., \& Rahman, M. M. (2011). Residual strength of chop strand mats glass fiber/epoxy composite structures: effect of temperature and water absorption. International Journal of Automotive and Mechanical Engineering, 4, 504-519.

Jeefferie, A. R., Mohamad, N., \& Ab Maulod, H. E. (2012). Processability of polypropylene-multiwalled carbon nanotubes (PP/MWCNTs) nanocomposites via direct melt compounding. Journal of Elastomers \& Plastics, 45(3), 239-251. (ISSN 0095-2443).

Liau, W. B. (1998). Dynamic mechanical relaxation of lightly cross-linked epoxidized natural rubber. Polymer, 40, 599-605.

Lopez-Manchado, M. A. \& Arroyo, M. (2001). Effect of the incorporation of PET fibers on the properties of thermoplastic elastomer based on PP/elastomer blends. Polymer, 42, 6557-6563.

Mangaraj, D. (2002). Elastomer blends. Rubber Chemistry and Technology, 75(3), 365427.

Mohamad, N., Muchtar, A., Ghazali, M. J., Mohd, D. H., \& Azhari, C. H. (2008). The effect of filler on epoxidised natural rubber-alumina nanoparticles composites. European Journal of Scientific Research, 24(4), 538-547.

Mohamad, N., Muchtar, A., Ghazali, M. J., Mohd, D. H., \& Azhari, C. H. (2010). Epoxidized natural rubber-alumina nanoparticle composites: optimization of mixer parameter via response surface methodology. Journal of Applied Polymer Science, 7, 183-189.

Mohamad, N., Muchtar, A., Ghazali, M. J., Mohd, D. H. and Azhari, C. H. (2011). Investigation on impact fracture of epoxidized natural rubber-alumina nanoparticle composites (ENRAN). Global Engineers \& Technologies Review, 1(2), 26-34.

Meyer, T. \& Keurentjes, J. (2005). Handbook of polymer reaction engineering. Wiley$\mathrm{VCH}$.

Nakason, C., Worlee, A., \& Salaeh, S. (2008). Effect of vulcanization systems on properties and recyclability of dynamically cured epoxidized natural rubber/polypropylene blends. Polymer Testing, 27, 858-869.

Nakason, C., Wannavilai, P., \& Kaesaman, A. (2006). Effect of vulcanization system on properties of thermoplastic vulcanizates based on epoxidized natural rubber /polypropylene blends. Polymer Testing, 25, 34-41.

Noriman, N. Z., Ismail, H., \& Rashid, A. A. (2010). Characterization of styrene butadiene rubber/recycled acronytrile-butadine rubber (SBR/NBR) blends: The effects of epoxidized natural rubber (ENR-50) as a compatibilizer. Polymer Testing, 29, 200-208.

Pire, M., Norves, S., Iliopoulos, I., Rossignol, B. L., \& Leibler, L. (2010). Epoxidized natural rubber/dicarboxylic acid self-vulcanized blends. Polymer, 5, 5903-5909.

Ravi Sankar, H., Srikant, R. R., Vamsi Krishna, P., Bhujanga Rao, V., \& Bangaru Babu, P. (2013). Estimation of the dynamic properties of epoxy glass fabric composites with natural rubber particle inclusions. International Journal of Automotive and Mechanical Engineering, 7, 968-980.

Setua, D. K. \& Gupta, Y. N. (2007). On the use of micro thermal analysis to characterize compatibility of nitrile rubber blends. Thermochimica Acta, 462, $32-37$. 
Tanrattanakul, V., Kosonmetee, K., \& Laokijcharoen, P. (2009). Polypropylene/ natural rubber thermoplastic elastomer: effect of phenolic resin as a vulcanizing agent on mechanical properties morphology. Journal of Applied Polymer Science, 112, 3267-3275.

Tedesco, A., Barbosa, R. V., Nachtigall, S. M. B., \& Mauler, R. S. (2002). Comparative Study of PP-MA and PP-MGA as compatibilizing agents on polypropylene/nylon 6 blends. Polymer Testing, 11, 11-15.

Thitithammawong, A., Nakason, C., Sahakaro, K., \& Noordermeer, J. (2007). Effect of different types of peroxides on rheological, mechanical, and morphological properties of thermoplastic vulcanizates based on natural rubber/polypropylene blends. Polymer Testing, 26, 537-546.

Umar, A. H., Zainudin, E. S., \& Sapuan, S. M. (2012). Effect of accelerated weathering on tensile properties of kenaf reinforced high-density polyethylene composites. Journal of Mechanical Engineering and Sciences, 2, 198-205.

Zurina, M., Ismail, H., \& Ratnam, C. T. (2006). Characterization of irradiation-induced crosslink of epoxidised natural rubber/ethylene vinyl acetate (ENR-50/EVA) blend. Polymer Degradation and Stability, 91, 2723-2730. 